\title{
Editorial: Theatre, Transnationalism and Economy: A Collaboration with Theatre Survey
}

\author{
CHARLOTTE M. CANNING
}

This special issue is unique in that it is the first time that this journal has collaborated with another to share the same set of questions ramified through the two journals' different missions. Editor Esther Kim Lee and I proposed to link Theatre Research International and Theatre Survey in order to explore how the ' 2008 worldwide economic crisis brought scholars of theatre and performance to re-examine how neoliberalism, economic nomadism, and transnationalism affect artistic practices', as we wrote in the call for papers. The response was impressive and demonstrated that performance scholars around the globe are thinking about these pressing issues in contiguous and contradictory ways.

Too rarely do we as a field put the major publications in performance in conversation with one another. We also wanted to acknowledge the long, intertwining histories of the International Federation for Theatre Research and the American Society for Theatre Research. Founded within a few years of each other, the two organizations have long continued each other's intellectual dialogues across conferences and other collaborations, but this is the first time that this discursive and dialogic relationship will be represented formally in our journals.

We were fortunate in that we had a terrific response to our call and had to make the very hard choice to decline many articles that would have made productive contributions to this conversation. But the eight articles (four for each journal) that we did select provide a deep and rich exploration of this crucial topic. It was compelling to both editors how certain topics and methods recurred, despite the two journals' different remits. One of the most striking was that of musical theatre, especially that which bears the seemingly national brand 'Broadway', but as David Savran points out in the Theatre Survey half of this special issue, 'this jet-setting genre needs to be analyzed less from a national or international perspective than a transnational one, which emphasizes interconnectedness and the cross-border fluidity of cultures and species of capital'. Two of the articles in this issue of TRI take up musicals, one from Broadway and the other on a series of South Korean musicals that did not start in the US but are clearly indebted to the genre. There are other connections that our readers can make from methods to examples, from geographic location to performance context, even from works cited to conclusions reached.

In the first article, 'Mythologizing the Global with the "Korean Original Musical"', Claire Maria Chambers uses musicals that originated in Seoul and that address local and tourist audiences differently to ask what the role of the national is in the global. Much discussion has focused on how globalization supersedes the national in many ways, but 
Chambers looks at how the national might reinscribe itself into the global, endeavouring to reassert its national primacy. All three shows she explores use a discursive process to negotiate Korea's relation to the world through performance. Chambers pushes her readers to consider the ways in which performance can foreground an always already global myth-making that undermines a temptation to see the global as emerging instead of seeing it as a long-standing performative.

Musicals are also the topic of Laura MacDonald and Myrte Halman's 'Geen Grenzen Meer: An American Musical's Unlimited Border Crossing', but their article focuses on how a performer's body itself can serve as the evidence and product of transnationalism. The authors explore Dutch actress Willemijn Verkaik's performances of Elphaba in Dutch, German and US productions of Wicked, particularly focusing on translation as it influences the construction of character, as well as how Verkaik's Dutch identity resonates within Wicked to transform her into a cultural diplomat. By tracing this performer's appearance in productions with different national settings, MacDonald and Halman offer a specific example of how the transnational circulates. This is done in part by questioning what remains of the 'American-ness' of the musical when it is performed in Germany or the Netherlands. Such questions offer ways for us to redefine notions of borders and re-examine our assumptions about what happens when commercial performance travels.

The third piece takes a very different approach from the other articles in the issue but, like the first two, also looks at performance in a commercial setting. In 'Megaship Economies and Transnational Maritime Performance', Anita González theorizes her own experiences on the front lines of the transnational, offering us an intimate view of how the transnational is produced and experienced from the perspective of a particularly circumscribed privilege as cruise ship staff in the Caribbean. González foregrounds the role of live performance - including her own as a 'destination lecturer' - in producing the transnational, as the ship's staff face pressure to provide live performance almost constantly to passengers and even staff members who do not routinely interact with passengers acquiesce. The 'maritime' is a rare category in studies of transnational performance, but until very recently it was virtually the only way movement across continental borders could occur. Expertise is as much a performance as anything that occurs on a formal stage, and González documents the extent and the limitations she experiences, reminding us that the 'terrestrial economies of class and power remain undisturbed' despite the conventions of more than a century of cruise ship transnational performance.

Finally, Katherine Mezur looks at a group of women who have intentionally exiled themselves so that they can perform the national in ways available to them only in a transnational setting. 'Stranger Communities: Art Labour and Berliner Butoh' examines a group of Japanese women performers who have intentionally chosen to develop their work outside Japan. Although the understanding of themselves as 'strangers' prevents the women from feeling at home either in Japan or anywhere else, it is also a category that has proved remarkably generative, allowing the performers to create rich work that would not have been possible had they not moved across geopolitical boundaries. Mezur particularly focuses on how these artists manipulate what they have lost and what they 
have gained through dwelling in 'stranger communities' to create powerful critiques of local, national and global identities, experiences and politics.

It has been six years since we were shaken by an economic crisis that was felt at varying levels of severity across the globe. The articles here taken together with those in the September $2014(55,3)$ issue of Theatre Survey demonstrate that performance is a very productive gauge of the impact of that economic upheaval. It is not, however, because these articles take up the year 2008 specifically, but because they allow us to see the ways in which performance has served historically and serves currently as a kind of bellwether for the movement of capital, culture and people. Eight articles in two journals (not to mention other articles in past issues of these same journals) provide us with one form of transnational cartography in that performance has travelled, does travel and will travel, and that travel always reveals the conditions, impact and possibilities for creating meaning out of lived experience. 